\title{
Borderline tuberculoid leprosy of the scalp
}

\author{
ISAAC NEERAJ SHAW, GIGI EBENEZER, B. BABU \& \\ GEETHA S. RAO \\ Schiffelin Leprosy Research \& Training Centre, Karigiri, Tamil Nadu, \\ India
}

Accepted for publication 5 April 2001

Summary A case of borderline tuberculoid leprosy involving the hairy scalp is reported. To the best of our knowledge, only two paucibacillary leprosy patients with scalp lesion have been reported, and in only one was the scalp covered with hair.

\section{Introduction}

Involvement of the scalp in leprosy is considered to be rare, and few cases with scalp lesions of leprosy have been reported. ${ }^{1-6}$ In most of these cases, the patients had multibacillary leprosy. We report a case of borderline tuberculoid leprosy on the hairy scalp.

\section{Case report}

A 30-year-old male presented an erythematous lesion with tingling sensation on the face and scalp of $1 \frac{1}{2}$ years duration. On examination, he had a well defined, warm, non-tender, erythematous swollen plaque of about $10 \times 15 \mathrm{~cm}$ on the butterfly area of the face and the whole of frontal and parietal area of the scalp (Figure 1). Eyebrows and scalp hairs were intact. Touch and pain sensations were impaired on the lesion and temperature sensation was absent. There was no nerve thickening or tenderness. Weakness of the orbicularis occuli and frontalis muscles was observed. A clinical diagnosis of borderline tuberculoid (BT) leprosy in type I reaction with lagophthalmus was made.

Skin smears from the routine and selective sites were negative for AFB. A biopsy from the skin lesion on the scalp showed discrete and confluent granulomas composed of epitheloid cells, lymphocytes, histiocytes, few Langerhans and foreign body type giant cells around blood vessels and skin adenexa. The dermis showed dilated lymphatic channels and blood vessels. The granulomas were seen replacing the base of hair follicles. The dermal nerves were inflamed. The granuloma fraction was $60 \%$. Acid fast stained sections showed few scattered bacilli within the nerves and in smooth muscles. They were predominantly granular and beaded.

The patient was started on the WHO paucibacillary regimen along with $40 \mathrm{mg}$ prednisolone in tablet form for type I reaction and weakness of the facial nerves. The dose of

Correspondence to: I. N. Shaw. 


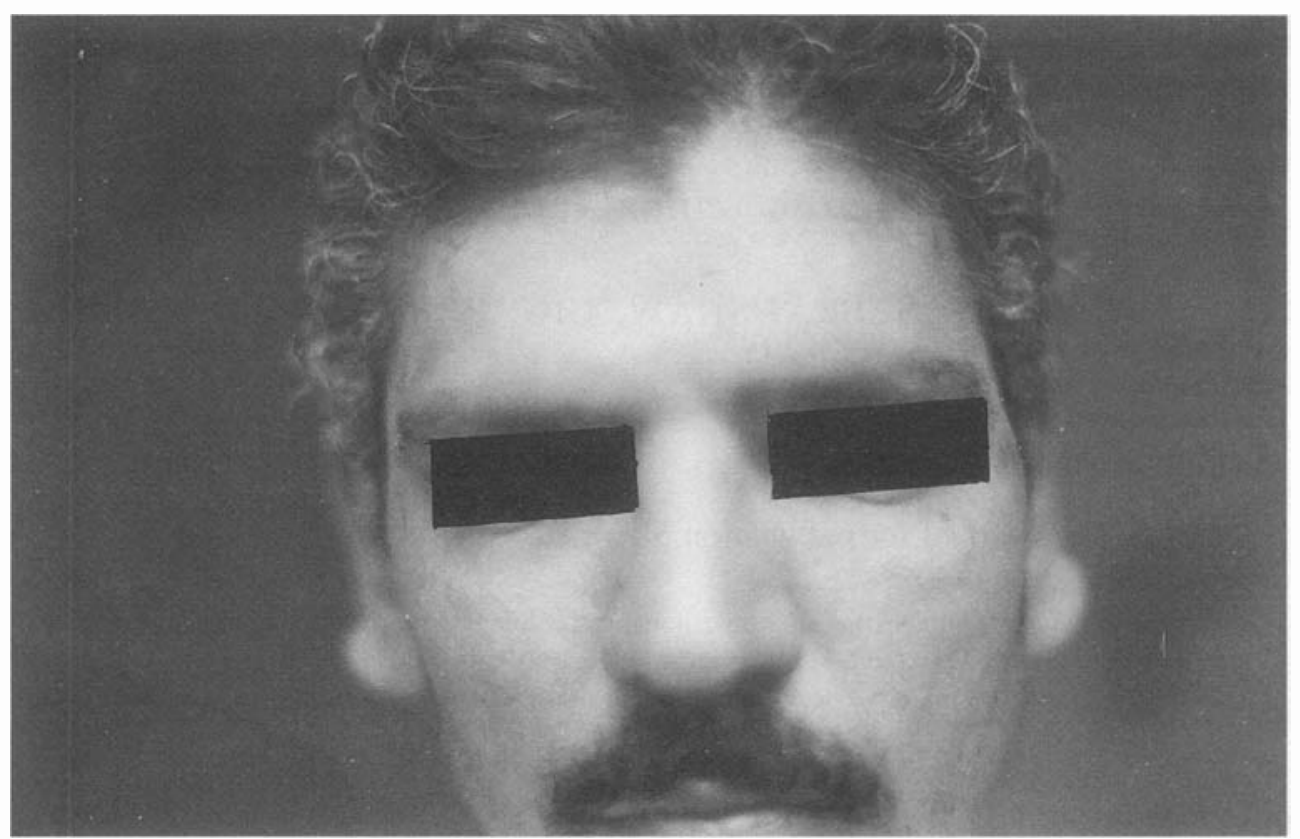

Figure 1. Clinical photograph showing the borderline tuberculoid lesion on the face extending to the hairy scalp.

prednisolone was gradually tapered according to the response, and it was stopped after 6 months. The patient was also recommended regular exercise for lagophthalmus.

\section{Discussion}

The scalp is considered to be an immune zone in leprosy. Anish demonstrated a higher temperature of the hairy scalp as compared to that of the forearm. ${ }^{7}$ As Mycobacterium leprae has a predilection for cooler parts of the body, ${ }^{8,9}$ the scalp is usually spared.

In most of the cases reported with scalp lesions the patients had either lepromatous or borderline lepromatous leprosy ${ }^{1-4}$ and in many of these cases the patients were bald. ${ }^{3}$ To the best of our knowledge, only one case each of tuberculoid and borderline tuberculoid with leprosy lesions on the scalp have been reported so far. ${ }^{5,6}$ While the tuberculoid plaque was present on the hairy occipital area of the scalp, ${ }^{9}$ the borderline tuberculoid lesion was seen on the scalp of an Indian who had performed the ritual of shaving of the scalp hair throughout his life. ${ }^{8}$ In our patient, the leprosy lesion involved the whole of the frontal and the parietal area of the scalp. Hair on the lesion remained intact in spite of the lesion having been present for $1 \frac{1}{2}$ years (Figure 1). Though rare, the hairy scalp can be involved in borderline tuberculoid leprosy, and the hair growth may appear normal.

\section{References}

${ }^{1}$ Bechelli UI, Silva DA, Olivaria AB. On histopathological findings in biopsies of apparently normal skin in cases of leprosy. Int J Lepr, 1945; 13: 175 (Abstract). 
2 Faget GH. Alopecia leprosa in the United States. Int J Lepr, 1946: 14: 42.

${ }^{3}$ Parikh AC, D'Souza NA, Chaulawala R, Ganapati R. Leprosy lesion on the scalp. Lepr Ind, 1974; 46: 39-42.

${ }^{4}$ Fleury RN, Tolentino MM, Opromolla OVA, Tonello C. Inapparent lepromatous leprosy in the scalp (paper read at International Leprosy Congress, 1973). Abstract in Int J Lepr, 1973; 45 : 580.

5 Parikh DA, Oberal C, Ganapati R. Involvement of scalp in leprosy. Lepr Ind, 1885; 57: 683-886.

${ }^{6}$ Gorpade A, Ramanan C, Manglani PR. Tuberculoid leprosy on hairy scalp: a case report. Lepr Rev, 1986; 59: 235237.

7 Anish SA. The relationship between surface temperature and dermal invasion in lepromatous leprosy. Int $J$ Lepr, 1971; 39: 838-851.

${ }^{8}$ Brand PW. Temperature variation and leprosy deformity. Int J Lepr, 1959; 27: 1-7.

9 Sabin TD, Ebner JD. Pattern of sensory loss in lepromatous leprosy. Int J Lepr, 1969; 37: 239-248. 